\title{
GLOBAL GEOCHEMICAL CYCLES OF CARBON, SULFUR AND OXYGEN
}

\section{JAMES C.G. WALKER}

Space Physics Research Laboratory, Department of Atmospheric and Oceanic Science, University of Michigan, Ann Arbor, MI 48109 (U.S.A.)

(Received January 9, 1984 ; revised and accepted September 19, 1984)

\begin{abstract}
Walker, J.C.G., 1986. Global geochemical cycles of carbon, sulfur and oxygen. In: P.A. Meyers and R.M. Mitterer (Editors), Deep Ocean Black Shales: Organic Geochemistry and Paleoceanographic Setting. Mar. Geol., 70: 159-174.

Time-resolved data on the carbon isotopic composition of carbonate minerals and the sulfur isotopic composition of sulfate minerals show a strong negative correlation during the Cretaceous. Carbonate minerals are isotopically heavy during this period while sulfate minerals are isotopically light. The implication is that carbon is being transferred from the oxidized, carbonate reservoir to the reservoir of isotopically light reduced organic carbon in sedimentary rocks while sulfur is being transferred from the reservoir of isotopically light sedimentary sulfide to the oxidized, sulfate reservoir. These apparently oppositely directed changes in the oxidation state of average sedimentary carbon and sulfur are surprising because of a well-established and easy to understand correlation between the concentrations of reduced organic carbon and sulfide minerals in sedimentary rocks. Rocks rich in reduced carbon are also rich in reduced sulfur. The isotopic and concentration data can be reconciled by a model which invokes a significant flux of hydrothermal sulfide to the deep sea, at least during the Cretaceous.
\end{abstract}

\section{INTRODUCTION}

Direct measurements of the rates of accumulation and the aereal extent of deep ocean black shales have not yet been sufficient to establish the impact of the sediments on global geochemical cycles. Data on the stable isotopes of carbon, however, show quite clearly that the Cretaceous, a time of deposition of deep ocean black shales, was also a time of markedly perturbed geochemical cycles for carbon, sulfur and oxygen.

\section{CARBON ISOTOPES}

Figure 1 compares the stable isotopic composition of the carbon in carbonate sediments from all over the world (Veizer et al., 1980) with the average concentration of reduced, organic carbon in Atlantic Ocean sediments (Brumsack and Lew, 1982). Large numbers of samples, indicated by the numbers in parentheses in the figure, were used to establish these average 


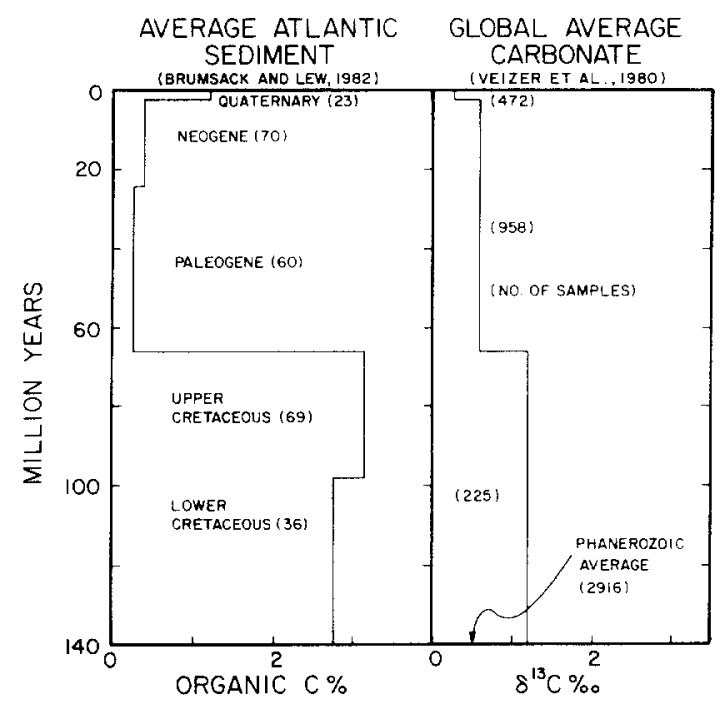

Fig.1. Average concentrations of reduced organic carbon in Atlantic sediments as a function of time and the isotopic composition of carbonate minerals. High carbon concentrations correlate with isotopically heavy carbonates.

behaviors as functions of time. The figure shows that globally averaged carbonate was isotopically heavy during the Cretaceous compared both with more recent geological time and also with an average for the whole of the Phanerozoic. At the same time, Atlantic Ocean sediments were, on average, much richer in organic carbon during the Cretaceous than during more recent geological periods. The concentration data do not, by themselves, prove that the rates of accumulation of organic carbon were large during the Cretaceous.

Figure 2 presents a summary budget of oceanic carbon as a first step in the explanation of the relationship between the isotopic composition of carbonate minerals and the organic carbon content of oceanic sediments. Carbon is supplied to the ocean and atmosphere at a rate of $25 \times 10^{12}$ moles $\mathrm{yr}^{-1}$ by the weathering of carbonate rocks and also by the volcanic and metamorphic generation of carbon dioxide (Walker, 1977). The total carbon content of ocean and atmosphere combined is $3.4 \times 10^{18}$ moles, principally in the form of bicarbonate ions in solution in sea water (Broecker, 1974). The residence time of carbon in the ocean can be calculated by dividing this quantity by the rate of supply. The result is $140 \times 10^{3}$ years, a time so short in geological terms that it can be assumed that the rates of supply and removal of carbon are in balance when averaged over time scales of millions of years.

Carbon is removed from the ocean and atmosphere by the precipitation of carbonate minerals with an isotopic composition, $\delta$, that is very nearly equal to the isotopic composition of sea water. Carbon is also removed from ocean and atmosphere by the precipitation, in sediments, of reduced organic 


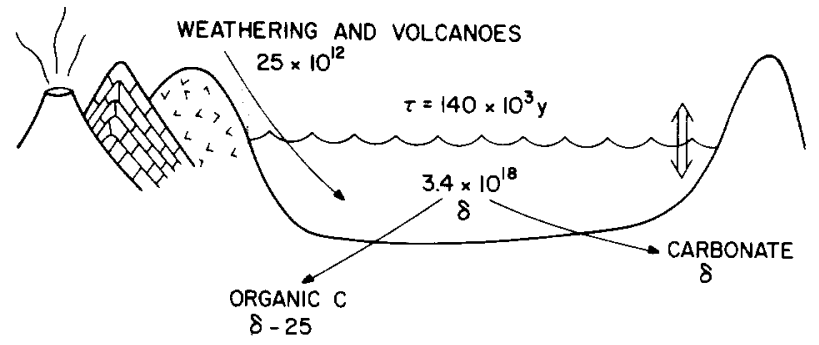

Fig. 2. A simple representation of the carbon budget of the ocean and atmosphere. Over time periods longer than a few hundred thousand years, the rate of removal of carbon by precipitation of carbonate minerals and organic carbon in sediments is equal to the rate of supply of carbon by weathering processes and by volcanic and metamorphic release of carbon dioxide. The isotopic budget is also balanced in the long-term average.

carbon. Because of isotopic fractionation in the course of photosynthesis, which favors the light isotope of carbon $\left({ }^{12} \mathrm{C}\right)$, the organic carbon is isotopically lighter than sea water by approximately 25 parts per thousand $(\% \circ)$. The relatively short residence time of carbon in the ocean and atmosphere implies that the supply and removal of carbon must be isotopically in balance as well as quantitatively in balance (Broecker, 1970). The average isotopic composition of the carbon supplied to the ocean must be equal, when averaged over times of millions of years, to the average isotopic composition of the carbon removed from the ocean.

This isotopic balance is illustrated in Fig.3. In equilibrium, the isotopic composition of the materials supplied to the ocean must equal the isotopic composition of the material removed from the ocean. This throughput is shown here at a composition of about $\delta{ }^{13} \mathrm{C}=-7 \%$. The input is composed of a mixture of carbonate and of organic carbon oxidized during weathering processes. The average isotopic composition of the organic carbon in sedimentary rocks subjected to weathering is $-24^{\circ} \%$ (Degens, 1969). The average isotopic composition of the carbonate minerals is $+1 \%$ (Veizer et al., 1980). These are supposed to contribute to the supply to the ocean in proportions $a$ and $1-a$. Carbon is rernoved from the ocean by precipitation of carbonate minerals with an isotopic composition $(\delta)$ that is equal to that of the ocean. Precipitation of sedimentary organic carbon with an isotopic composition equal to $\delta-25$ plays a role also. The relative proportions of these two are $1-b$ and $b$. As the figure shows, if the proportion of organic carbon in the output is equal to the proportion of organic carbon in the input (that is, if $a=b$ ), then the isotopic composition of newly deposited carbonate will be equal to the average isotopic composition of old, weathered carbonate (namely, $\delta=1$ ). More generally:

$b-a=(\delta-1) / 25$

The unusually heavy global average carbonate of the Cretaceous implies that $b$ was greater than $a$ during this time, which means that the rate of 


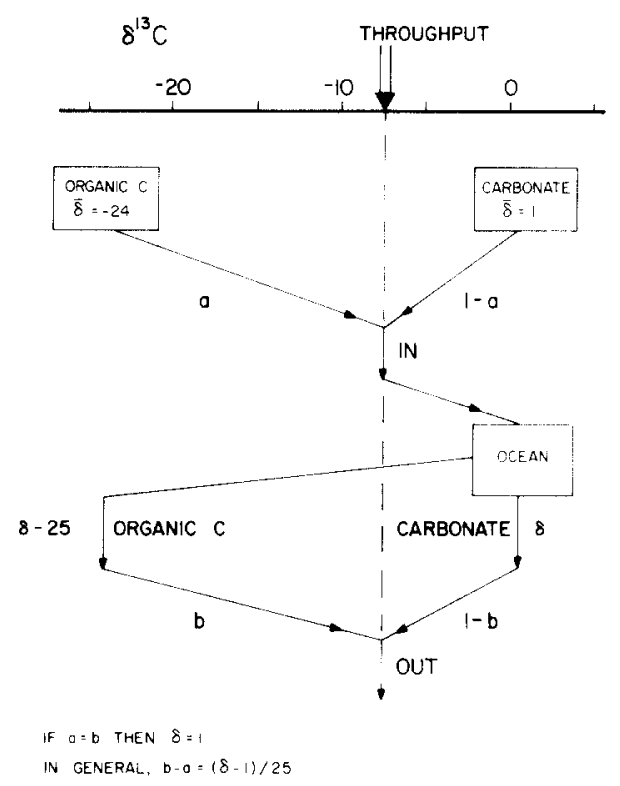

Fig. 3. The factors that govern the isotopic compositon of oceanic carbon and of carbonate minerals. Departures of the isotopic composition of new carbonate from that of average old carbonate imply a transfer of carbon between oxidized and reduced reservoirs.

burial of organic carbon in new sediments exceeded the rate of weathering of organic carbon in old sediments. This excess of burial rate over weathering rate caused a positive excursion in the isotopic composition of oceanic carbonate and the composition of carbonate minerals precipitated from the ocean. When averaged over times of $10^{5}$ years or more, both isotopic balance and material balance were maintained during this excursion. But there was a net transfer of carbon from the oxidized, carbonate reservoir to the reduced, organic carbon reservoir.

The sedimentary organic carbon was produced, by photosynthesis, from oxidized carbon. Corresponding to the net transfer of carbon from the oxidized to the reduced reservoirs was a release of oxygen. The cumulative amount of this release is readily calculated by multiplying $b-a$, calculated from the isotopic data, by the flux of carbon through the ocean-atmosphere system. For simplicity this flux is assumed to be constant. Results of the calculation are illustrated in Fig.4. The isotopic data illustrated here have been reported by Scholle and Arthur (1980) from a number of sites in and around the Atlantic Ocean. Large numbers of samples were collected and analyzed to provide high time resolution. The hatched area in the figure corresponds to the envelope of approximately 10 profiles analyzed by Scholle and Arthur. Newer data reveal much more detail (M. Arthur, pers. commun., 1984). The very substantial departure of the carbonate isotopic composition from a Phanerozoic average of about $\delta{ }^{13} \mathrm{C}=1 \%$ yields the cumulative release of oxygen shown on the right of the figure. Over a period 


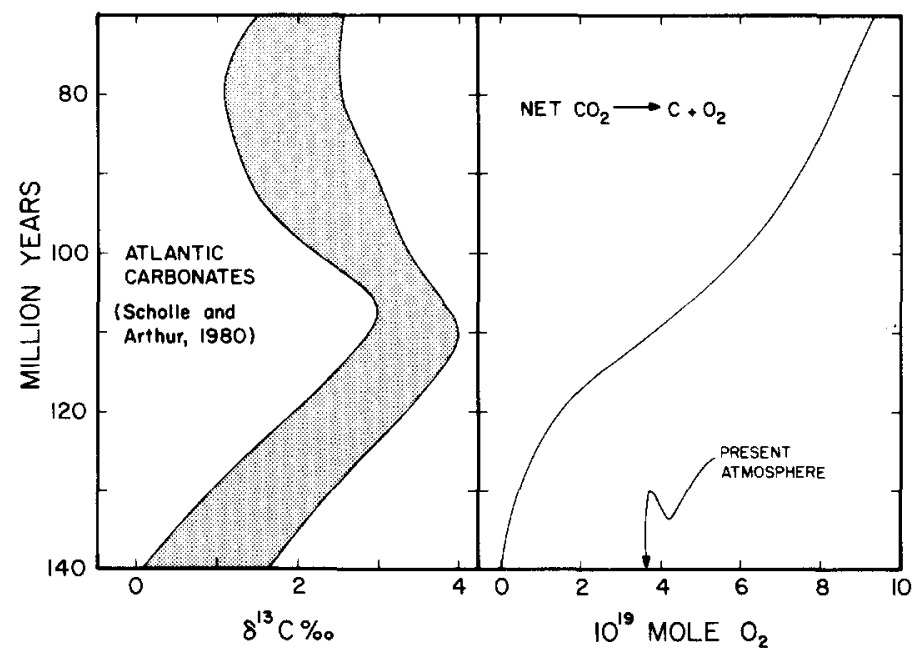

Fig.4. Time-resolved isotopic composition of carbonates from the Atlantic Ocean region. Heavy isotopic compositions imply the release of oxygen in the carbon cycle in the substantial amounts shown on the right of the figure.

of $60 \mathrm{~m} . \mathrm{y}$. it appears that the cumulative release of oxygen from the global geochemical cycle of carbon amounted to considerably more than the amount of oxygen now in the atmosphere. It seems hardly likely that this very large amount of oxygen could have accumulated in the atmosphere. It was presumably consumed by a transfer from reduced to oxidized reservoirs in the global geochemical cycle of some other element.

\section{SULFUR ISOTOPES}

This other element was evidently sulfur (Garrels and Lerman, 1981, 1984). Iron appears to be much less important (Walker, 1977; Holland, 1978). Figure 5 compares the carbon isotopic data of Scholle and Arthur, where just the mid-point of the envelope is plotted, with sulfur isotope data reported by Claypool et al. (1980). The sulfur data refer to the average of a large number of samples of sulfate evaporites. As the figure shows, the sulfur in the sulfate minerals becomes isotopically lighter as the carbon in the carbonate minerals becomes isotopically heavier. There is a strong negative correlation between these two isotopic records based on completely different minerals, samples, and locations. As I shall show below, the interpretation of the sulfur isotope record is quite analogous to that of the carbon isotope record (see, for example, Garrels and Lerman, 1981, 1984; Berner and Raiswell, 1983). Reduced sulfur is isotopically light. Oxidized sulfur is isotopically heavy. The minimum in isotopic composition at about $110 \mathrm{~m} . \mathrm{y}$. ago corresponds to a time of net transfer of sulfur from the reduced reservoir to the oxidized reservoir.

The sulfur budget of the ocean is summarized in Fig.6. The oceanic reservoir, almost entirely in the form of dissolved sulfate ions, is more than 


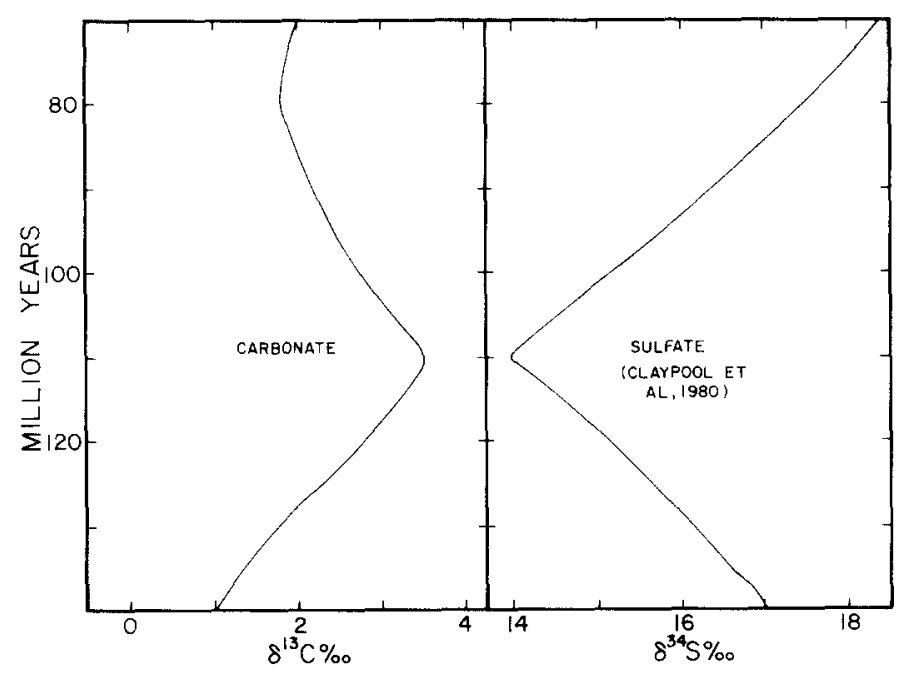

Fig. 5. The isotopic composition of sedimentary sulfate minerals, shown on the right, is negatively correlated with the isotopic composition of carbonate minerals shown on the left.

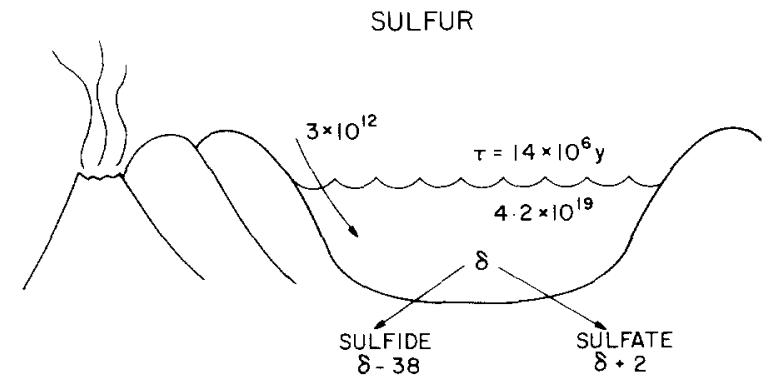

Fig.6. An abridged representation of the sulfur budget of the ocean. Because of a relatively small rate of supply and a relatively large oceanic reservoir, the residence time of sulfur in the ocean exceeds $10 \mathrm{~m}$.y. Sulfur is removed from the ocean by precipitation of sulfate minerals that are a little heavier than sea water sulfate and sedimentary sulfides that are a lot lighter.

10 times as large as the oceanic bicarbonate reservoir (Broecker, 1974). At the same time, the rate of supply of sulfur, provided by weathering and dissolution of sulfide and sulfate minerals and the volcanic release of sulfur gases, is almost 10 times smaller than the rate of supply of carbon to the ocean (Meybeck, 1979; Zehnder and Zinder, 1980; Berresheim and Jaeschke, 1983). As a result, the residence time of sulfur in the ocean is 100 times longer than the residence time of carbon. The sulfur residence time, $14 \times 10^{6}$ years, is so long that it is possible for departures from equilibrium, both in material balance and isotopic balance, to persist for geologically significant periods of time. The possibility of departures from equilibrium must be kept in mind, although I shall assume equilibrium for simplicity in the analysis that follows. 
The sulfate that is removed from the ocean by precipitation of evaporite minerals is heavier than sea water by approximately $1.2 \%$ while the isotopic composition of the sulfide minerals precipitated by biogenic sulfate reduction in anoxic environments, is lighter than the sulfate by an average of approximately $40 \%$ (Claypool et al., 1980). Therefore, sea-water sulfate and evaporite minerals become isotopically heavier when the rate of deposition of sulfide exceeds the rate of weathering of sulfide. Alternatively, they become lighter when more sulfide is being oxidized than is being deposited. This was the situation at the Aptian-Albian boundary about 110 m.y. ago.

A simple calculation of the relative rates of change of carbon and sulfur isotopic compositions has been presented by Veizer et al. (1980). Assume that the carbon budget of the ocean is in isotopic and material balance. Then, as shown in Fig.3:

$$
\left(\bar{\delta}_{\mathrm{c}}-\alpha_{\mathrm{c}}\right) a_{\mathrm{c}} F_{\mathrm{c}}+\bar{\delta}_{\mathrm{c}}\left(1-a_{\mathrm{c}}\right) F_{\mathrm{c}}=\left(\delta_{\mathrm{c}}-\alpha_{\mathrm{c}}\right) b_{\mathrm{c}} F_{\mathrm{c}}+\delta_{\mathrm{c}}\left(1-b_{\mathrm{c}}\right) F_{\mathrm{c}}
$$

where $F_{\mathrm{c}}$ is the flux of carbon through the ocean, $a$ is the fraction of the input flux that is reduced, $b$ is the fraction of the output flux that is reduced, $\delta$ is the isotopic composition of seawater, $\bar{\delta}_{\mathrm{c}}$ the average composition of carbonate rocks, and $\alpha_{c}$ is the difference in isotope ratios between oxidized and reduced carbon. The equation simplifies to:

$\delta_{c}=\bar{\delta}_{c}+\alpha_{c}\left(b_{c}-a_{c}\right)$

Assume that the sulfur budget of the ocean is also in isotopic and material balance. This does not mean that the sulfate concentration or isotope ratio of seawater does not change with time, but that any change is slow relative to the flow of sulfur through the sea (with a characteristic time of $14 \times 10^{6}$ years). Then the analysis already applied to carbon yields:

$\delta_{\mathrm{s}}=\bar{\delta}_{\mathrm{s}}+\alpha_{\mathrm{s}}\left(b_{\mathrm{s}}-a_{\mathrm{s}}\right)$

an expression for the isotopic composition of seawater, $\delta_{\mathrm{s}}$, in terms of the average composition of sulfate minerals, $\bar{\delta}_{\mathrm{s}}$, the fractionation between reduced and oxidized sulfur, $\alpha_{s}$, and the fractions of the input and output fluxes that are reduced.

Any change in the isotopic composition of sea water that results from transfer between oxidized and reduced reservoirs can be expressed as:

$\Delta \delta_{\mathrm{c}}=\alpha_{\mathrm{c}} \Delta\left(b_{\mathrm{c}}-a_{\mathrm{c}}\right)$

and:

$\Delta \delta_{\mathrm{s}}=\alpha_{\mathrm{s}} \Delta\left(b_{\mathrm{s}}-a_{\mathrm{s}}\right)$

where it is assumed that $\bar{\delta}$ and $\alpha$ do not change.

Now assume that oxidized carbon is reduced on a global scale by reaction with reduced sulfur or the reverse, without any net consumption or release of oxygen, according to the stoichiometric relationship shown in Fig.7 (Garrels and Lerman, 1981). The flux of carbon from oxidized to reduced reservoirs is $F_{\mathrm{c}}\left(b_{\mathrm{c}}-a_{\mathrm{c}}\right)$. The flux of sulfur from reduced to oxidized reservoirs is $F_{\mathrm{s}}\left(a_{\mathrm{s}}-b_{\mathrm{s}}\right)$. Oxygen balance implies: 


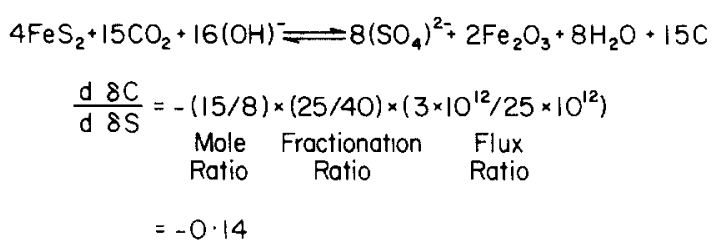

Fig.7. Calculation of the slope of a plot of carbon isotopic composition against sulfur isotopic composition if it is assumed that all of the oxygen released by the transfer of carbon from oxidized to reduced reservoirs is consumed by an equivalent transfer of sulfur from the reduced to the oxidized reservoirs.

$F_{\mathrm{c}}\left(b_{\mathrm{c}}-a_{\mathrm{c}}\right) / 15=F_{\mathrm{s}}\left(a_{\mathrm{s}}-b_{\mathrm{s}}\right) / 8$

or:

$\Delta\left(b_{\mathrm{c}}-a_{\mathrm{c}}\right)=15 F_{\mathrm{s}} / 8 F_{\mathrm{c}} \Delta\left(a_{\mathrm{s}}-b_{\mathrm{s}}\right)$

So:

$\Delta \delta_{\mathrm{c}}=\alpha_{\mathrm{c}}\left(15 F_{\mathrm{s}} / 8 F_{\mathrm{c}}\right)\left(-\Delta \delta_{\mathrm{s}} / \alpha_{\mathrm{s}}\right)$

or:

$\mathrm{d} \delta_{\mathrm{c}} / \mathrm{d} \delta_{\mathrm{s}}=-15 \alpha_{\mathrm{c}} F_{\mathrm{s}} / 8 \alpha_{\mathrm{s}} F_{\mathrm{c}}$

which is the expression of Veizer et al. (1980) illustrated in Fig.7. The relationship predicts, for the relative fluxes given in Figs.2 and 6, that a plot of the isotopic composition of carbonate minerals against the isotopic composition of sulfate minerals should have a slope of -0.14 . As Veizer et al. (1980) have shown, this prediction is well satisfied by data for the

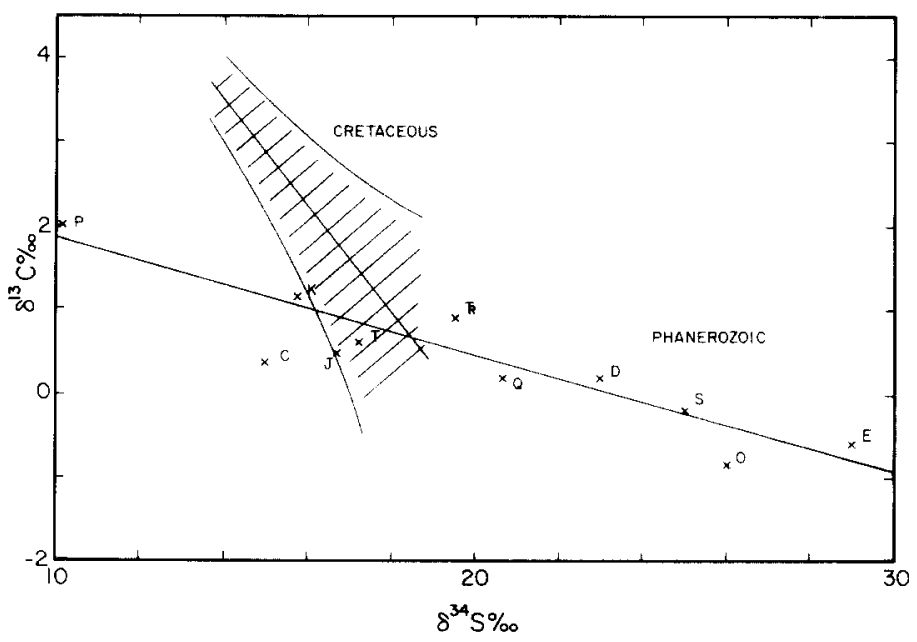

Fig.8. Average data on carbon and sulfur isotopic compositions during the Phanerozoic are shown by crosses (Veizer et al., 1980). The line through the crosses shows the slope calculated in Fig.7. The cross-hatched region denotes the data for the Cretaceous that were plotted in Fig. 5. 
entire Phanerozoic, plotted as averages by period. Their results are reproduced in Fig.8. Figure 8 also shows on the same scale the Cretaceous data that were plotted in Fig.5. These Cretaceous data reveal a negative correlation between carbon and sulfur isotopes, as already noted, but the slope of this negative correlation is markedly steeper than the slope predicted in Fig. 7 which is the slope that well reproduces the Phanerozoic average data.

The overall theoretical picture is pleasing, even if the discrepancy of the time-resolved Cretaceous data is a potential source of concern. The idea is that imbalances of oxidation and reduction in the geochemical cycle of carbon are completely cancelled out by imbalances of oxidation and reduction in the geochemical cycle of sulfur (Garrels and Perry, 1974; Garrels et al., 1976; Veizer et al., 1980; Garrels and Lerman, 1981, 1984). Thus, when carbonate becomes isotopically heavier, sulfate becomes isotopically lighter. At the same time, the store of free oxygen, mostly in the atmosphere, does not vary significantly even when very large amounts of oxygen are being transferred between the carbon and sulfur cycles.

\section{REDUCED CARBON AND SULFUR IN SEDIMENTS}

Unfortunately, this theoretical description of oxidation-reduction balance in the geochemical cycles of carbon and sulfur is completely at variance with the well-established correlation between the sulfide content of sediments and the organic carbon content of sediments (Goldhaber and Kaplan, 1974). Figure 9 shows a representative illustration of this correlation (Berner, 1982; Brumsack and Lew, 1982). High concentrations of organic carbon in sediments generally correspond to high concentrations of sulfide

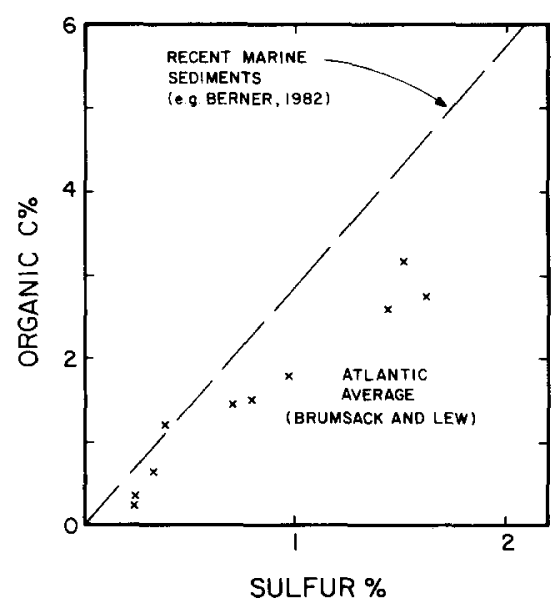

Fig.9. The positive correlation between the concentration of reduced organic carbon in sediments and the concentration of sulfide. High carbon concentrations are associated with high sulfide concentrations because the sulfide is produced by bacterial sulfate reduction in anaerobic, carbon-rich environments. 
minerals. This positive correlation is not surprising. Sulfate is reduced to sulfide by anaerobic microorganisms in anaerobic sediments (see, for example, Berner, 1980). High concentrations of organic carbon promote the establishment of anaerobic conditions or anaerobic conditions facilitate the preservation of high concentrations of organic carbon. Either way, it is hard to imagine the sedimentary environment in which precipitation of reduced organic carbon and reduced sulfide minerals would be negatively rather than positively correlated. Similarly, it is hard to imagine what feedback mechanism would cause such a negative correlation on a global scale. Unusual circumstances must be invoked to explain a situation in which the transfer of carbon from oxidized to reduced reservoirs is accompanied by the transfer of sulfur from reduced to oxidized reservoirs. Berner and Raiswell (1983), for example, invoke shifts in the sites of carbon burial to account for changes in the globally averaged ratio of reduced carbon to sulfur in sediments.

Under most circumstances, however, the operation of the sedimentary cycle of weathering and deposition must cause carbon and sulfur to move together between oxidized and reduced reservoirs. The sedimentary cycles of carbon and sulfur cannot buffer the amount of free oxygen in the atmosphere. As shown in Fig.9, the ratio of carbon to sulfur in average mean sediments is about 2.8 by weight or 7.5 by numbers of atoms. Figure 10 shows that this ratio of carbon to sulfur would yield a slope of the plot of carbon isotopes against sulfur isotopes that is small and positive. At the same time, transfer of carbon and sulfur between oxidized and reduced reservoirs would lead to release or consumption of substantial amounts of oxygen. Both of these predictions are contradicted by the data. What is the source of this contradiction?

Could there be a large source of sulfide other than the weathering of sedimentary rocks, which could absorb the extra oxygen released during the Cretaceous as a result of excess burial of sedimentary organic carbon and sulfide? Could there be important terms in the geochemical sulfur budget that have so far been overlooked in this discussion?

AVERAGE SEDIMENTS

$$
\begin{gathered}
15 \mathrm{CO}_{2}+2\left(\mathrm{SO}_{4}\right)^{22}+0.5 \mathrm{Fe}_{2} \mathrm{O}_{3}+2 \mathrm{H}_{2} \mathrm{O} \\
\rightleftharpoons 15 \mathrm{C}+\mathrm{FeS}_{2}+4(\mathrm{OH})^{-}+18 \cdot 75 \mathrm{O}_{2} \\
\quad \frac{d 8 \mathrm{C}}{d 8 \mathrm{~S}}=+0.01
\end{gathered}
$$

Fig.10. Calculation of the slope of a plot of carbon isotopic composition against sulfur isotopic composition if it is assumed that reduced carbon and sulfur in sedimentary rocks are positively correlated as shown in Fig.9. The positive slope predicted by this calculation contradicts the data for the Phanerozoic and for the Cretaceous, shown in Fig. 8 . The calculation also predicts a large net release of oxygen. 


\section{SULFUR BUDGET}

Indeed, the sulfur budget so far described is unbalanced, both in mass and with respect to isotopes, so there is room for additional terms in the budget. The unbalanced sulfur budget is summarized in Fig.11. The presentday rate of supply of natural sulfur (after correction for pollution) has been estimated by Meybeck (1979) at $3 \times 10^{12}$ moles $\mathrm{yr}^{-1}$ while the rate of deposition of sulfide minerals in sediments has been estimated by Berner (1982) as $1.3 \times 10^{12}$ moles $\mathrm{yr}^{-1}$. The rate of precipitation of sulfate minerals is negligible today because of the absence of extensive evaporite basins. The sedimentary sulfur budget is therefore apparently unbalanced at present, with the rate of supply exceeding the rate of removal. Similarly, the isotopic budget is apparently unbalanced. The supply by rivers has an average isotopic composition of about $+10 \%$ (Holser and Kaplan, 1966), while the sedimentary sulfide is isotopically light, possibly about $-18 \%$. Evidently, the isotopic composition of the supply is not equal to the isotopic composition of the output. Because of the long residence time of sulfur in the ocean it is entirely possible that these budgets are in fact unbalanced at the present time, although balanced in the long term by episodic deposition of sulfate evaporites. This interpretation is frequently offered (Berner, 1972). On the other hand, it is possible that the sulfur budget is in balance both with respect to mass and with respect to isotopes, but that there are other terms in the sulfur budget.

The potential importance of sea-floor hydrothermal systems to the oceanic sulfur budget has been argued by Edmond et al. (1979) and McDuff and Edmond (1982). Figure 12 presents a balanced sulfur budget that is consistent with the findings of McDuff and Edmond. The river fluxes and sedimentary sulfide flux have not been changed. The flux into the ocean of hydrothermal sulfide has been assigned a value of $10^{12}$ moles $\mathrm{yr}^{-1}$ (McDuff and Edmond, 1982), and the rate at which sulfate is removed from the ocean by reaction between sea water and hot, sea-floor basalt is then given a value of $2.7 \times 10^{12}$ moles $\mathrm{yr}^{-1}$, just sufficient to balance the oceanic sulfur budget.

UNBALANCED S BUDGET

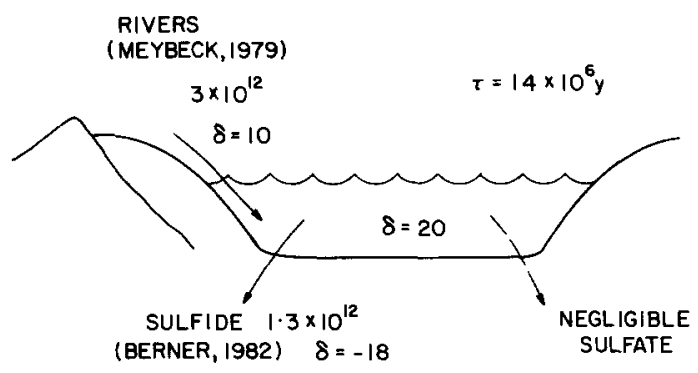

Fig.11. The conventional budget of oceanic sulfur is at present unbalanced both with respect to mass and with respect to isotopic composition. 


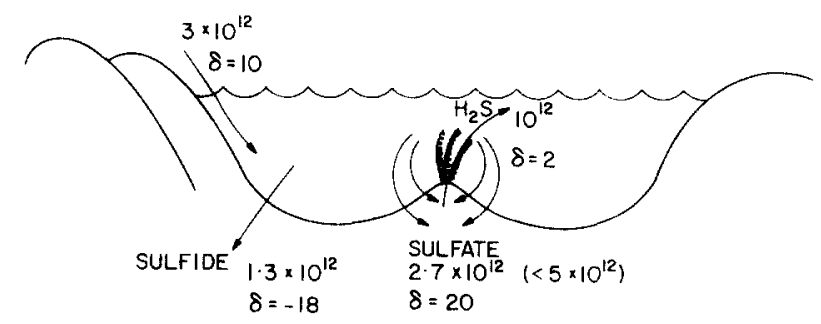

Fig.12. The sulfur budget can be balanced by including a source of hydrogen sulfide in sea-floor hydrothermal systems and a sink for oceanic sulfate that results from the interaction of sea water with hot sea-floor basalt. This budget is balanced both with respect to mass and with respect to isotopic composition.

Measurements on hydrothermal minerals yield an isotopic composition for the hydrothermal sulfide of about $\delta^{34} \mathrm{~S}=+2 \%$ (Skirrow and Coleman, 1982). This isotopic composition reflects a mixture of mantle sulfur leached from sea-floor basalt and sea-water sulfur abiotically reduced from sulfate to sulfide in interactions with hot basalt. If it is assumed that all of the sulfate carried in solution into the sea floor by percolating sea water is precipitated, then this sulfate removed from the ocean will be isotopically unfractionated. It will have the same isotopic composition as sea water, namely $\delta=+20 \%$. These assumptions and values, illustrated in Fig.12, yield a sulfur budget that is isotopically balanced as well as balanced with respect to mass. There are no obvious contradictions in assuming that sea-floor hydrothermal systems have a significant impact on the sulfur budget of the ocean and, indeed, that the present day budget is approximately balanced both with respect to mass and with respect to isotopes. On the other hand, there is no unambiguous evidence for the major role that I am assigning to sea-floor hydrothermal activity.

\section{IMPACT OF SEA-FLOOR HYDROTHERMAL SYSTEMS}

Suppose, now, that it is the sulfide released to the ocean by sea-floor hydrothermal systems that consumes the excess oxygen released when carbon and sulfur are transferred from the oxidized sedimentary reservoir to the reduced sedimentary reservoir. (Such consumption is not likely to be detectable as an anomalous concentration of dissolved oxygen near midocean ridges.) Since the hydrothermal sulfide is isotopically light such a process would yield the observed negative correlation between carbon and sulfur isotopes rather than the positive correlation that would be expected for the sedimentary system alone. Moreover, since the hydrothermal sulfide is not as light, isotopically, as sedimentary sulfide the sulfur isotopic composition would not vary as rapidly with carbon isotopic composition as would be the case for the purely sedimentary system. The Cretaceous data shown in Fig. 8 exhibit just this behavior. The relatively small variation in sulfur 
isotopic composition could result from oxidation of a sulfide source that is not as light as sedimentary sulfide.

Figure 13 shows how the Cretaceous isotopic data can be reconciled with the observed positive correlation between reduced carbon and sulfide in sedimentary rocks in terms of a presumed contribution of sea-floor hydrothermal sulfide. The figure plots various quantities as a function of the carbon isotopic composition of carbonate minerals. The Phanerozoic average carbon isotopic composition is $\delta^{13} \mathrm{C}=+1 \%$. The corresponding flux of organic carbon to sediments is $10^{13}$ moles $\mathrm{yr}^{-1}$, as shown in the figure, and the flux of sulfide to sedimentary rocks with the usual ratio of sulfide to carbon is $1.3 \times 10^{12}$ moles $\mathrm{yr}^{-1}$. If it is arbitrarily assumed that the rate of oxidative weathering of sedimentary organic carbon and sulfide does not vary with time, then heavier carbon isotopic compositions correspond to larger rates of burial of sedimentary organic carbon and sulfide, as shown in Fig.13. These larger rates of burial of reduced carbon and sulfur correpond to a net release of oxygen. The theory assumes that this extra oxygen is consumed by sulfide released from sea-floor hydrothermal systems. The figure shows the required flux of hydrothermal sulfide and the way it varies

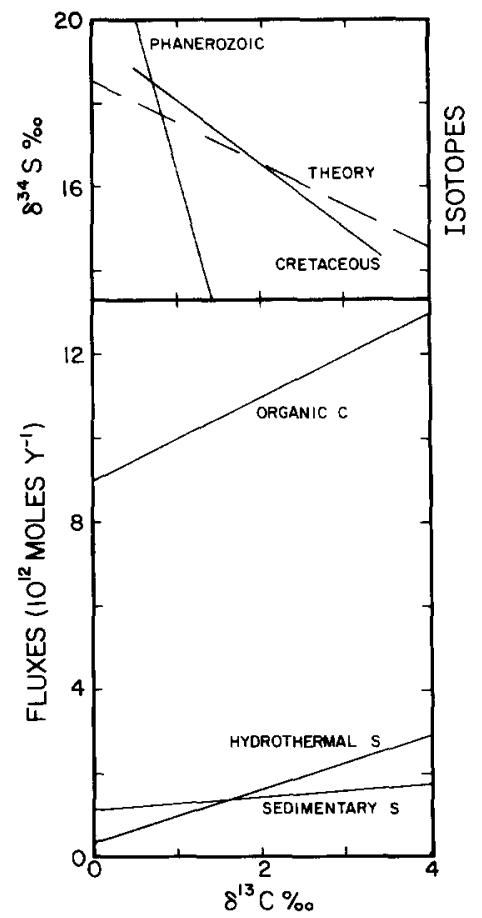

Fig.13. The Cretaceous isotopic data for both carbon and sulfur can be reconciled in a model that provides the indicated fluxes of hydrothermal sulfide to the deep sea. In this model it is assumed that there is no large change in the amount of free oxygen in the atmosphere, nor any change in the ratio of reduced carbon to sulfide in average sediments. 
with carbon isotopic composition. The variation of isotopic composition from 1 to $4 \%$, comparable with the variation in the Cretaceous data of Scholle and Arthur (1980) requires an increase in the flux of hydrothermal sulfide from $10^{12}$ to $3 \times 10^{12}$ moles $\mathrm{yr}^{-1}$, as shown in Fig.13. Sea-floor spreading rates have varied (Hays and Pitman, 1973; Rea and Scheidegger, 1979) and it seems likely that hydrothermal activity has varied also.

If the hydrothermal sulfide has an isotopic composition of $+2 \%$ and the sedimentary sulfide has an isotopic composition of $-18 \%$, the predicted variation of sulfur isotopic composition with carbon isotopic composition is as shown by the dashed line at the top of Fig.13. This theoretical result agrees quite well with the data for the Cretaceous. It therefore seems that the Cretaceous isotopic data can be reasonably explained without any change in the atmospheric oxygen reservoir and without any postulated change in the usual ratio of sedimentary organic carbon to sulfide, in terms of variations in the flux of hydrothermal sulfide to the ocean. The Phanerozoic average isotopic data are not reproduced by this simple theory, but it is quite possible that this discrepancy would be resolved by a theory that allowed for variations with time in the sulfate content of the ocean and perhaps also in the rate of erosion and weathering of the continents. Alternatively, a variation in the globally averaged ratio of carbon to sulfur in shales may have been important (Berner and Raiswell, 1983).

Obviously, my speculative suggestions can not be considered the last word on this subject. More careful analysis is needed, and more time-resolved data on carbon and sulfur isotopes would be most useful. Nonetheless, I feel that a strong case can be made for an important contribution to the sulfur budget by sea-floor hydrothermal systems and I feel that the Cretaceous isotopic data for carbon and sulfur provide evidence in support of this important role.

\section{A SPECULATIVE MECHANISM}

It might reasonably be asked what process or set of processes might cause the fluxes of sedimentary carbon and sulfide and the flux of hydrothermal sulfide to vary together in the manner illustrated in Fig.13. Clearly, the hydrothermal flux does not directly respond to the sedimentary flux. Any causal interaction must go in the other direction. I suggest that enhanced hydrothermal activity leads to a larger flux of sulfide to the deep sea. This extra sulfide draws down the oxygen content of ocean and atmosphere enough to promote anoxic conditions in parts of the deep sea. These anoxic conditions in turn lead to enhanced rates of burial of organic carbon and sulfide in sea-floor sediments (Holland, 1973; Walker, 1974, 1980). In terms of this model, therefore, oceanic anoxic events are caused by reduced concentrations of atmospheric oxygen which result from enhanced rates of sea-floor hydrothermal activity. Published theories for oceanic anoxic events and the origin of deep-sea black shales have not dealt with possible depressions in the partial pressure of atmospheric oxygen (Schlanger and Cita, 1982). This neglect should probably be corrected. 


\section{ACKNOWLEDGEMENTS}

My interest in this subject was stimulated by P.A. Meyers, who introduced me to the literature on deep ocean black shales. This research was supported in part by the National Aeronautics and Space Administration under Grant NAGW-176 to The University of Michigan.

\section{REFERENCES}

Berner, R.A., 1972. Sulfate reduction, pyrite formation, and the oceanic sulfur budget. In: D. Dryssen and D. Jagner (Editors), The Changing Chemistry of the Oceans. Wiley, New York, N.Y., pp.347-361.

Berner, R.A., 1980. Early Diagenesis: A Theoretical Approach. Princeton University Press, Princeton, N.J., 241 pp.

Berner, R.A., 1982. Burial of organic carbon and pyrite sulfur in the modern ocean: Its geochemical and environmental significance. Am. J. Sci., 282: 451-473.

Berner, R.A. and Raiswell, R., 1983. Burial of organic carbon and pyrite sulfur in sediments over Phanerozoic time: A new theory. Geochim. Cosmochim. Acta, 47: 855-862.

Berresheim, H. and Jaeschke, W., 1983. The contribution of volcanoes to the global atmospheric sulfur budget. J. Geophys. Res., 88: 3732-3740.

Broecker, W.S., 1970. A boundary conditon on the evolution of atmospheric oxygen. J. Geophys. Res., $75: 3553-3557$.

Broecker, W.S., 1974. Chemical Oceanography. Harcourt Brace Jovanovich, New York, N.Y., $214 \mathrm{pp}$.

Brumsack, H.J. and Lew, M., 1982. Inorganic geochemistry of Atlantic Ocean sediments with special reference to Cretaceous black shales. In: U. von Rad, K. Hinz, M. Sarntheim and E. Seibold (Editors), Geology of the Northwest African Continental Margin. Springer, Berlin, pp.661-685.

Claypool, G.E., Holser, W.T., Kaplan, I.R., Sakai, H. and Zak, I., 1980. The age curves of sulfur and oxygen isotopes in marine sulfate and their mutual interpretation. Chem. Geol., 28: 199-260.

Degens, E.T., 1969. Biogeochemistry of stable carbon isotopes. In: G. Eglinton and M.T.J. Murphy (Editors), Organic Geochemistry: Methods and Results. Springer, Berlin, pp.304-329.

Edmond, J.M., Measures, C., McDuff, R.E., Chan, L.H., Collier, R., Grant, B., Gordon, L.I. and Corliss, J.B., 1979. Ridge crest hydrothermal activity and the balances of the major and minor elements in the ocean: The Galapagos data. Earth Planet. Sci. Lett., 46: 1-18.

Garrels, R.M. and Lerman, A., 1981. Phanerozoic cycles of sedimentary carbon and sulfur. Proc. Natl. Acad. Sci. USA, 78: 4652-4656.

Garrels, R.M. and Lerman, A., 1984. Coupling of the sedimentary sulfur and carbon cycles - An improved model. Am. J. Sci., 284: 989-1007.

Garrels, R.M. and Perry, E.A., 1974. Cycling of carbon, sulfur, and oxygen through geologic time. In: E. Goldberg (Editor), The Sea, Vol. 5. Wiley-Interscience, New York, N.Y., pp.303-336.

Garrels, R.M., Lerman, A. and Mackenzie, F.T., 1976. Controls of atmospheric $\mathrm{O}_{2}$ and $\mathrm{CO}_{2}$ : Past, present and future. Am. Sci., 64: 306-315.

Goldhaber, M.B. and Kaplan, I.R., 1974. The sulfur cycle. In: E. Goldberg (Editor), The Sea, Vol. 5. Wiley-Interscience, New York, N.Y., pp.569-656.

Hays, J.D. and Pitman, W.C., 1973. Lithospheric plate motion, sea level changes and climatic and ecological consequences. Nature, 246: 18-22.

Holland, H.D., 1973. Ocean water, nutrients, and atmospheric oxygen. In: Proc. Symposium on Hydrogeochemistry and Biogeochemistry, Vol. 1. The Clarke Co., Washington, D.C., pp.68-81. 
Holland, H.D., 1978. The Chemistry of the Atmosphere and Oceans. Wiley-Interscience, New York, N.Y., 351 pp.

Holser, W.T. and Kaplan, I.R., 1966. Isotope geochemistry of sedimentary sulfates. Chem. Geol., 1: 93-135.

McDuff, R.E. and Edmond, J.M., 1982. On the fate of sulfate during hydrothermal circulation at mid-ocean ridges. Earth Planet. Sci. Lett., 57:117-132.

Meybeck, M., 1979. Concentrations des eaux fluviales en élements majeurs et apports en solution aux oceans. Rev. Geol. Dyn. Geogr. Phys., 21: 215-246.

Rea, D.K. and Scheidegger, K.F., 1979. Eastern Pacific spreading rate fluctuation and its relation to Pacific area volcanic episodes. J. Volcanol. Geotherm. Res., 5: 135-148.

Schlanger, S.O. and Cita, M.B., 1982. Nature and Origin of Cretaceous Carbon-Rich Facies. Academic Press, London, 229 pp.

Scholle, P.A. and Arthur, M.A., 1980. Carbon isotope fluctuations in Cretaceous pelagic limestones: Potential stratigraphic and petroleum exploration tool. Bull. Am. Assoc. Pet. Geol., 64: 67-87.

Skirrow, R. and Coleman, M.L., 1982. Origin of sulfur and geothermometry of hydrothermal sulphides from the Galapagos Rift, $86 \mathrm{~W}$. Nature, 299:142-144.

Veizer, J., Holser, W.T. and Wilgus, C.K., 1980. Correlation of ${ }^{13} \mathrm{C} /{ }^{12} \mathrm{C}$ and ${ }^{34} \mathrm{~S} /{ }^{32} \mathrm{~S}$ secular variations. Geochim. Cosmochim. Acta, 44:579-587.

Walker, J.C.G., 1974. Stability of atmospheric oxygen. Am. J. Sci., 274: 193-214.

Walker, J.C.G., 1977. Evolution of the Atmosphere. Macmillan, New York, N.Y., 318 pp.

Walker, J.C.G., 1980. The oxygen cycle. In: O. Hutzinger (Editor), The Natural Environment and the Biogeochemical Cycles. Springer, Berlin, pp.87-104.

Zehnder, A.J.B. and Zinder, S.H., 1980. The sulfur cycle. In: O. Hutzinger (Editor), The Natural Environment and the Biogeochemical Cycles. Springer, Berlin, pp.105-145. 